\title{
Assessment of indoor air quality at an electronic cigarette (Vaping) convention
}

\author{
Rui Chen ${ }^{1} \cdot$ Angela Aherrera $^{1} \cdot$ Chineye Isichei $^{1} \cdot$ Pablo Olmedo $^{1,2} \cdot$ Stephanie Jarmul ${ }^{1} \cdot$ Joanna E. Cohen $^{3}$. \\ Ana Navas-Acien ${ }^{1,2} \cdot$ Ana M. Rule ${ }^{1}$
}

Received: 24 January 2017 / Accepted: 22 August 2017 / Published online: 29 December 2017

(c) The Author(s) 2017. This article is published with open access

\begin{abstract}
E-cigarette (vaping) conventions are public events promoting electronic cigarettes, in which indoor use of e-cigarettes is allowed. The large concentration of people using e-cigarettes and poor air ventilation can result in indoor air pollution. In order to estimate this worst-case exposure to e-cigarettes, we evaluated indoor air quality in a vaping convention in Maryland (MD), USA. Real-time concentrations of particulate matter $\left(\mathrm{PM}_{10}\right)$ and real-time total volatile organic compounds (TVOCs), $\mathrm{CO}_{2}$ and $\mathrm{NO}_{2}$ concentrations were measured. Integrated samples of air nicotine and $\mathrm{PM}_{10}$ concentrations were also collected. The number of attendees was estimated to range from 75 to 600 at any single observation time. The estimated 24-h timeweighted average (TWA) $\mathrm{PM}_{10}$ was $1800 \mu \mathrm{g} / \mathrm{m}^{3}$, 12-fold higher than the EPA 24-h regulation $\left(150 \mu \mathrm{g} / \mathrm{m}^{3}\right)$. Median (range) indoor TVOCs concentration was $0.13(0.04-0.3) \mathrm{ppm} . \mathrm{PM}_{10}$ and TVOC concentrations were highly correlated with $\mathrm{CO}_{2}$ concentrations, indicating the high number of people using e-cigarettes and poor indoor air quality. Air nicotine concentration was $125 \mu \mathrm{g} / \mathrm{m}^{3}$, equivalent to concentrations measured in bars and nightclubs. E-cigarette aerosol in a vaping convention that congregates many e-cigarette users is a major source of $\mathrm{PM}_{10}$, air nicotine and VOCs, impairing indoor air quality. These findings also raise occupational concerns for e-cigarette vendors and other venue staff workers.
\end{abstract}

\section{Intoduction}

Electronic cigarettes (also called Electronic Nicotine Delivery Systems and e-cigarettes) are battery-powered devices that deliver an aerosol with or without nicotine and flavorings, instead of burning tobacco [1]. E-cigarette use is rapidly increasing worldwide [2]. According to CDC reports from 2014, $12.6 \%$ of adults (40.2 million) had ever tried an e-cigarette and about $3.7 \%$ of adults (11.8 million)

Ana M. Rule

arule@jhsph.edu

1 Department of Environmental Health and Engineering, Johns Hopkins Bloomberg School of Public Health, Baltimore, MD, USA

2 Department of Environmental Health Sciences, Columbia University Mailman School of Public Health, New York, NY, USA

3 Department of Health, Behavior and Society and Institute for Global Tobacco Control, Johns Hopkins Bloomberg School of Public Health, Baltimore, MD, USA were currently using e-cigarettes every day or some days in the United States [3]. Among the current users, 2.4 million were middle-aged and high school-aged students [4]. Estimated global sales of e-cigarettes reached \$2 billion in 2014 and is projected to increase to $\$ 10$ billion in 2017 [5].

E-cigarettes have been heavily promoted through vape shop advertisements, social media, and "vaping conventions". Vaping conventions, or vape expos, are public events that promote the newest device trends and flavors, and provide information on e-cigarette products. These events attract a large number of e-cigarette enthusiasts, vendors, and local residents, and allow (and promote) e-cigarette use inside the venues. Williams [6] reported that 90 vaping conventions were held in 37 different locations in the US from 2010 to 2015 (average of 15 per year). As part of the attraction, entertainment events, such as "cloud competitions" and several trick competitions (artistic plumes) are scheduled during the day. These competitions reward those who can generate the largest, densest or most artistic plume with free merchandise [7].

Growing evidence indicates that inhaled e-cigarette aerosol is composed of compounds with known adverse 
health effects. In a recent study, nicotine concentration in ecigarette aerosol ranged between $0.5-15.4 \mathrm{mg}$ per 15 puffs, measured in 20 series of 15 puffs each [8]. Several studies have also shown that e-cigarette aerosol contains particulate matter [9, 10], formaldehyde and other volatile organic compounds (VOCs), such as toluene, p,m-xylene [11], as well as tobacco-specific nitrosamines (TSNAs), aldehydes, and metals [12].

Unlike traditional combustible products, e-cigarettes do not generate "side-stream" smoke from the end of a lit cigarette. Secondhand exposure from e-cigarettes, like the one measured in this study, mainly comes from the aerosol exhaled by e-cigarette users. However, few studies have analyzed the composition of this secondhand e-cigarette aerosol, which impacts indoor air quality, exposing bystanders to secondhand aerosol with potentially adverse health effects [13]. Recent studies have found that exhaled ecigarette aerosol contains nicotine, propylene glycol, glycerol, particulate matter, ultra-fine particles, and VOCs [1416]. Another study found that exposure to the secondhand aerosol was associated with an increase in serum cotinine levels similar to traditional cigarette smokers [17]. The large number of people using e-cigarettes indoors at vaping conventions may increase health risks among attendees and convention workers. Some government agencies have already proposed to prohibit the use of e-cigarettes in workplaces and enclosed public spaces [9, 16, 18].

There are currently no published studies on the health effects of secondhand e-cigarette aerosol exposure. Environmental epidemiological evidence, however, suggests adverse effects of particulate matter from any source related to both short-term and long-term exposures [16]. Nicotine exposure has also been associated with increased risk of cardiovascular, respiratory, gastrointestinal disorders, decreased immune response, and DNA mutations leading to cancer [19].

Our objective was to assess indoor air quality at a vaping convention by measuring airborne particulate matter, TVOCs, and aerosol nicotine. The study findings provide information on potential indoor air contamination from ecigarette use and can inform policies that restrict indoor use of e-cigarettes, and protect attendees and workers.

\section{Matererials and methods}

\section{Sampling}

Air sampling was carried out during a vaping convention in April 2016 at the Maryland State Fairgrounds in Timonium, MA, USA. The venue size was $55 \times 49 \times 5 \mathrm{~m}^{2}\left(13,475 \mathrm{~m}^{3}\right)$. Sampling started outdoors around $30 \mathrm{~min}$ after the vaping convention began, at 12:27 pm. Real-time and integrated samples were collected during a period of up to $7 \mathrm{~h}$. All sampling equipment was placed inside a backpack and carried around the convention venue. Three teams of two people each took turns carrying the backpack inside the venue. Special occurrences such as closing windows, holding trick competitions or vaping competitions, and changing of sampling locations were recorded. Information on the number of attendees, intensity of the smell, and visibility were estimated every $15 \mathrm{~min}$, and recorded on a $\log$ sheet accompanied by photographs. The number of attendees was estimated by counting how many people were in the immediate area and extrapolating to the total area of the venue. Intensity of smell was categorized as weak, strong or intolerable, and visibility was categorized as normal, low or zero visibility. Outdoor sampling was conducted before entering the venue $(33 \mathrm{~min})$ to establish baseline values, and then two more times during the sampling period. A total of $58 \mathrm{~min}$ were sampled outside, compared to $342 \mathrm{~min}$ indoors. The time-integrated samples (particulate matter (PM) and nicotine) reflect a combination of indoor and outdoor sampling (400 $\mathrm{min}$ ).

Particulate matter smaller than $10 \mu \mathrm{m}\left(\mathrm{PM}_{10}\right)$ was measured in real-time with a personal aerosol particle monitor (SidePak $^{\text {TM }}$ AM510; TSI, Shoreview, MN, USA) designed for screening purposes, with 1-min resolution. Air flow rate was calibrated at $1.7 \mathrm{~L} / \mathrm{min}$ per manufacturer instructions using an electronic flow calibrator (Bios DryCal Defender; Brandt Instruments, Prairieville, LA, USA). The SidePak had been factory-calibrated within 6 months, and zeroed the day before. Integrated sampling of $\mathrm{PM}_{10}$ was conducted with Personal Environmental Monitors ${ }^{\circledR}$ (PEM) with $37 \mathrm{~mm}$ PVC filters (Both PEM and filters from SKC, Inc., Eighty Four, PA) at $4 \mathrm{~L} / \mathrm{min}$.

Airborne nicotine was collected using passive samplers originally developed by Hammond and Leaderer [20]. Samplers consist of $37 \mathrm{~mm}$ glass fiber filters impregnated with sodium bisulfate and assembled in modified polystyrene sampling cassettes, covered with a porous diffusion membrane. Two samplers were used in passive mode and two were connected to pumps for active mode. Active sampling was conducted at a sampling rate of $3 \mathrm{~L} / \mathrm{min}$ as previously described by Lopez et al. [21]. Two field blanks were collected for quality control.

All nicotine filters were extracted in heptane with $1 \%$ Triethylamine with an internal standard (isoquinoline) and were analyzed using gas chromatography with flame thermoionic detector (Shimadzu, Kyoto, Japan). Airborne nicotine concentrations were calculated by dividing the amount of nicotine collected by each filter $(\mathrm{mg})$ by the volume of air sampled $\left(\mathrm{m}^{3}\right)$.

Total TVOCs, carbon dioxide $\left(\mathrm{CO}_{2}\right)$, nitrogen dioxide $\left(\mathrm{NO}_{2}\right)$, temperature and relative humidity were measured using a multi-gas monitor (GrayWolf; Sensing Solutions, 
Shelton, CT, USA), which is also designed as a screening tool. The TVOC sensor is a photoionization detector. Air passes through a filter membrane to exclude particles and liquids, and is exposed to a high-energy ultra violet lamp (10.6 electron volt $(\mathrm{eV})$ ) which ionizes the air molecules. These ions are measured by a collection electrode and converted into a current, which is proportional to concentration. All molecules with an ionization potential (IP) lower than the energy of the UV lamp will be ionized, and the instrument response reflects all components that are ionized. This means that unless there is a single gas pollutant, the response reflects the mixture, or "total VOCs" (in ppm). The standard $\mathrm{CO}_{2}$ sensor employed by GrayWolf utilizes dual band, folded path NDIR (Non-Dispersive Infrared) technology with a reference channel for selfcompensation.

Temperature and relative humidity were also measured using real-time data loggers (HOBO U10-003; onset Computer Corporation, Bourne, MA, USA). Both GrayWolf and HOBO Data Loggers were set to collect at 1-min interval. We also attempted to measure carbon monoxide (CO) but there was a technical problem with the $\mathrm{CO}$ sensor and the data had to be discarded. Similar to the SidePak monitor, the Graywolf monitor had been factory-calibrated within 6 months of our assessment, and zeroed the day before, as recommended by the manufacturer.

\section{Data analysis}

Data from the direct-reading devices were plotted and matched to the time each team entered and exited the venue to compare the indoor and outdoor aerosol concentrations. One-hour and 24-h time-weighted average (TWA) concentrations were calculated for all pollutants sampled. For the 24-h TWA, it was assumed that concentration during the time not sampled was $0 \mathrm{mg} / \mathrm{m}^{3}$ [22]. Descriptive analyses (mean, median, range and interquartile range), $t$-tests, Whitney-Mann-Wilcoxon test and Spearman correlations were performed with StataSE software, version 12.0 (Stata Corp, College Station, TX) and $p$-values less than 0.05 were considered statistically significant.

\section{Results}

Sampling for nicotine, TVOCs, $\mathrm{CO}_{2}, \mathrm{NO}_{2}$, temperature and relative humidity lasted for $400 \mathrm{~min}$. Real-time sampling of $\mathrm{PM}_{10}$ stopped after $303 \mathrm{~min}$ due to instrument failure. Based on team observations, the number of attendees in the venue was estimated to range from 75 to 600 at any single observation time. The visibility in the venue at peak occupancy was very low as shown in Fig. 1, and the intensity of smell was categorized as strong during that time.

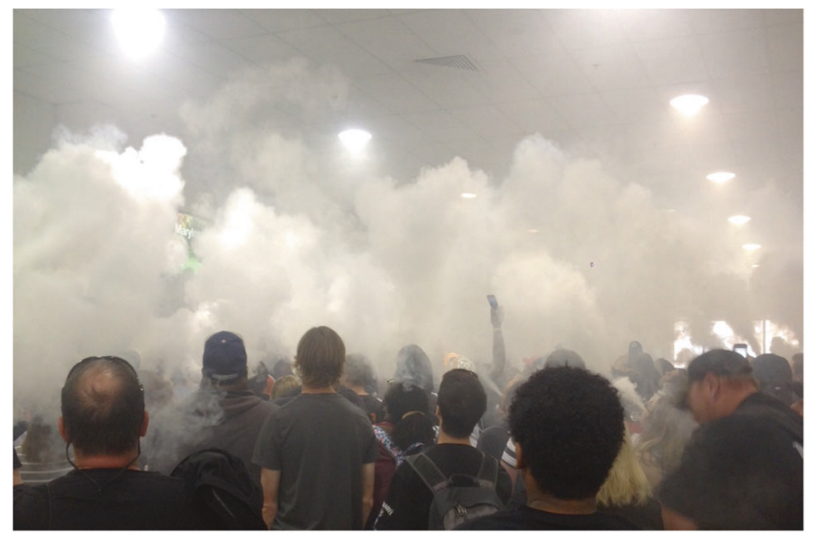

Fig. 1 Photograph taken at the vaping convention around $2 \mathrm{pm}$, in April 2016, MD, USA

Real-time changes of all gases and $\mathrm{PM}_{10}$, together with special activities and entry/exit of the venue while wearing the monitors are summarized in Fig. 2. PM 10 , TVOCs, and $\mathrm{CO}_{2}$ concentrations significantly decreased during the personnel transition outside the venue. There were two trick (artistic plume) competitions and one big plume size competition that were held inside the venue and included in the indoor measurements. Median (interquartile range) of the indoor and outdoor concentrations, as well as concentrations during trick competition and plume size competition, of $\mathrm{PM}_{10}$, TVOCs, $\mathrm{CO}_{2}$, and $\mathrm{NO}_{2}$ are summarized in Table 1.

The overall $\mathrm{PM}_{10}$ median concentration (range) using the real-time monitor over the entire sampling time was 10,436 $(9-17,860) \mu \mathrm{g} / \mathrm{m}^{3}$ and the mean was $8,699 \mu \mathrm{g} / \mathrm{m}^{3}$, which includes all indoor and outdoor measurements. The 24-h TWA $\mathrm{PM}_{10}$ was calculated to be $1,800 \mu \mathrm{g} / \mathrm{m}^{3}$ and also includes all indoor and outdoor measurements. The median indoor $\mathrm{PM}_{10}$ concentration was $11,370 \mu \mathrm{g} / \mathrm{m}^{3}$, which was 950 times higher than outside the venue $\left(12 \mu \mathrm{g} / \mathrm{m}^{3}\right)$. $\mathrm{PM}_{10}$ concentrations using integrated sampling were 8,850 and $8,429 \mu \mathrm{g} / \mathrm{m}^{3},\left(\right.$ mean $\left.=8,639 \mu \mathrm{g} / \mathrm{m}^{3}\right)$, which was consistent with the overall mean $\mathrm{PM}_{10}$ concentration obtained from the real-time monitor.

The median (range) TVOCs concentration over the 7-h sampling period was $0.12(0.04-0.3) \mathrm{ppm}$. The median indoor concentration $(0.13 \mathrm{ppm})$ was 2 times higher than the outdoor concentration of $0.05 \mathrm{ppm}(p$-value $<0.0001)$. The median indoor $\mathrm{CO}_{2}$ concentration was $873 \mathrm{ppm}$, which was 2.4 times higher than the outdoor $\mathrm{CO}_{2}$ concentration (364 $\mathrm{ppm})$. The median indoor $\mathrm{NO}_{2}$ concentration was $0.09 \mathrm{ppm}$, which was almost $1 / 4$ of the median outdoor $\mathrm{NO}_{2}$ concentrations of $0.32 \mathrm{ppm}$ ( $p$-value $<0.0001$ ). The 1-h TWA indoor $\mathrm{NO}_{2}$ concentration was calculated to be $0.10 \mathrm{ppm}$. During the vaping competition, median TVOCs were $67 \%$ higher ( $p$-value $<0.0001)$ and $\mathrm{CO}_{2}$ concentrations were $28 \%$ higher $(p$-value $<0.0001)$ compared to the remaining 


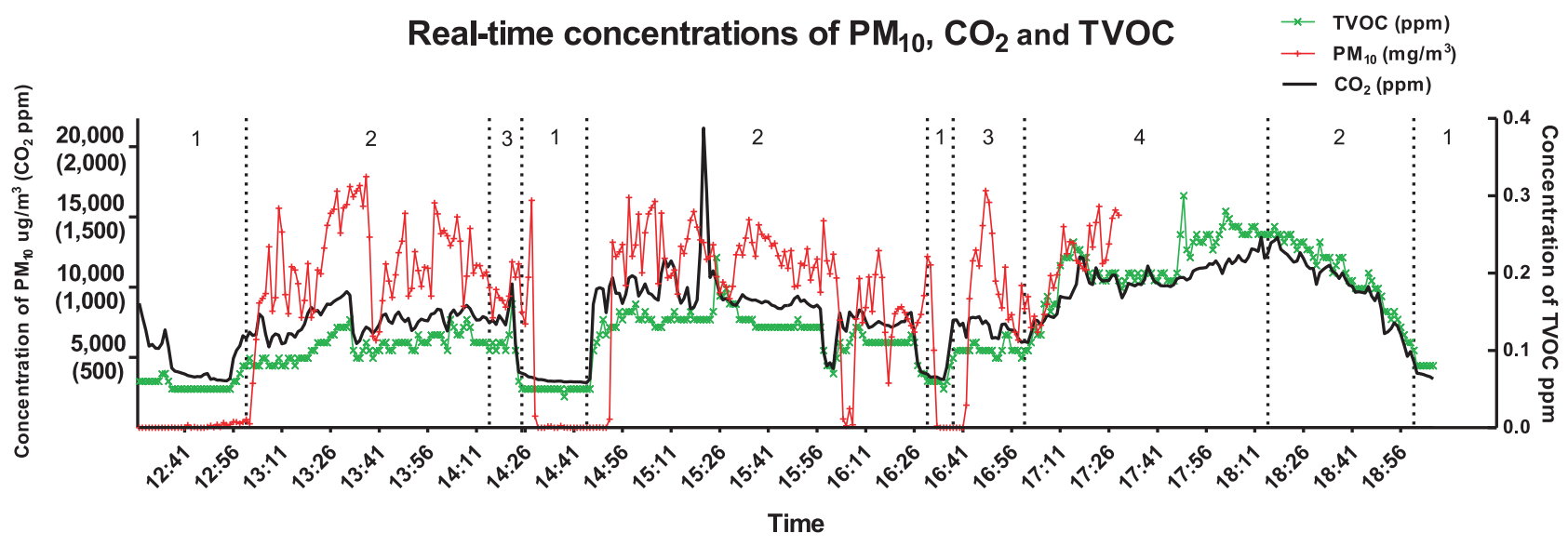

1=outside the venue; $2=$ =inside the venue; $3=$ trick competition; 4=vaping competition

Fig. 2 Real-time changes of $\mathrm{PM}_{10}, \mathrm{CO}_{2}$, and TVOC concentrations

Table 1 Summary of $\mathrm{PM}_{10}$ and gases measured during the convention

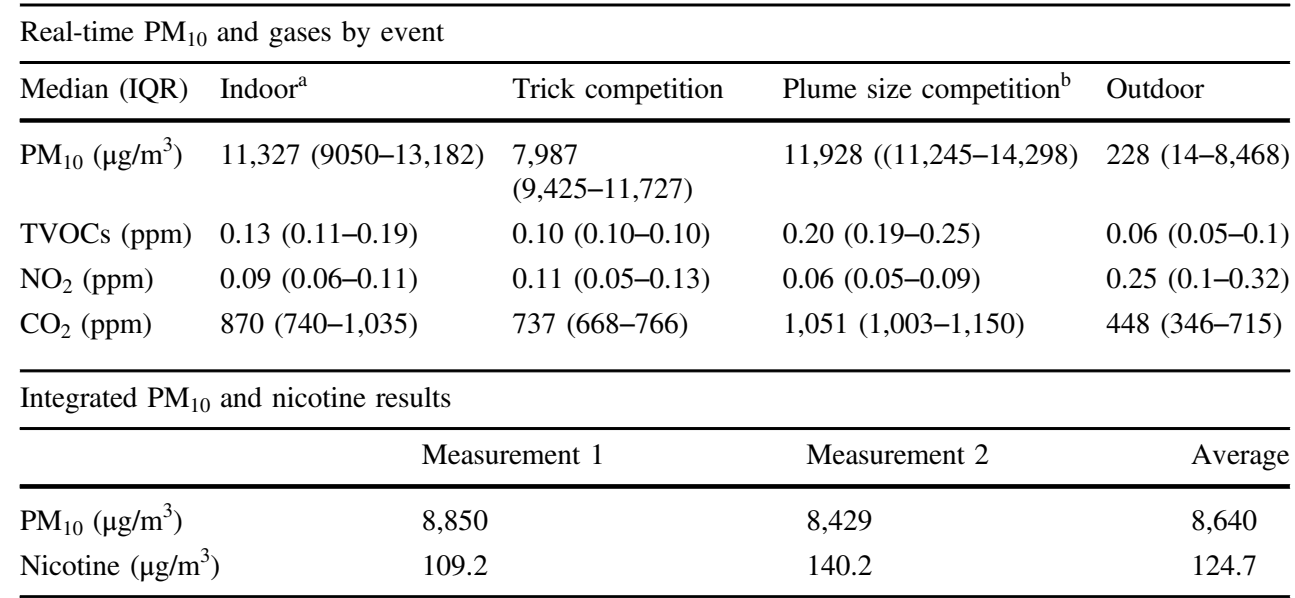

${ }^{a}$ Indoor data included measurements from Trick competition and Plume size competition

${ }^{b} \mathrm{PM}_{10}$ monitor stopped during plume size competition and only partial data are available indoor measures, supporting that e-cigarettes were the main source of those indoor air contaminants and that their concentrations further increased during the time of the competitions. For $\mathrm{PM}_{10}$, unfortunately, the monitor stopped $24 \mathrm{~min}$ after the beginning of the competition and the comparison with the remaining indoor sampling is limited.

The mean indoor temperature $\left(77^{\circ} \mathrm{F}\right)$ was significantly higher than the outdoor temperature $\left(74^{\circ} \mathrm{F}\right) \quad(p$-value $<$ $0.0001)$, while relative humidity was similar between inside $(38 \%)$ and outside $(39 \%)$ ( $p$-value $=0.06)$.

Aerosol nicotine concentrations using active sampling were 109.2 and $140.2 \mu \mathrm{g} / \mathrm{m}^{3}$ for each of the two monitors, and using passive sampling both monitors were below the limit of detection (LOD) due to the small sampling rate (25 $\mathrm{ml} / \mathrm{min})$. Blanks were also <LOD.

$\mathrm{PM}_{10}$ concentrations were positively correlated with $\mathrm{CO}_{2}$ concentrations during all the sampling periods, with $r=$ 0.76 ( $p$-value $<0.0001)$. A similar correlation was found between TVOCs and $\mathrm{CO}_{2}(r=0.81, p$-value $<0.0001)$ (Fig. 3). $\mathrm{NO}_{2}$ was negatively correlated to $\mathrm{PM}_{10}$, TVOCs and $\mathrm{CO}_{2}$.

\section{Discussion}

Indoor concentrations of $\mathrm{PM}_{10}$, TVOCs, $\mathrm{CO}_{2}$ and airborne nicotine significantly increased during a vaping convention in Maryland that attracted more than 1,000 people in April 2016, markedly impairing indoor air quality. TVOCs and $\mathrm{CO}_{2}$ concentrations, moreover, further increased during the cloud competitions, a time during the convention when people competed to produce the largest aerosol plumes. The detection of airborne nicotine, a specific marker not related to other sources of air pollution, supports that e-cigarettes are a major source of indoor air pollutants during vaping conventions. To the best of our knowledge, this is the first 
Fig. 3 Correlations between $\mathrm{PM}_{10}$, TVOCs, $\mathrm{CO}_{2}$, and $\mathrm{NO}_{2}$ concentrations

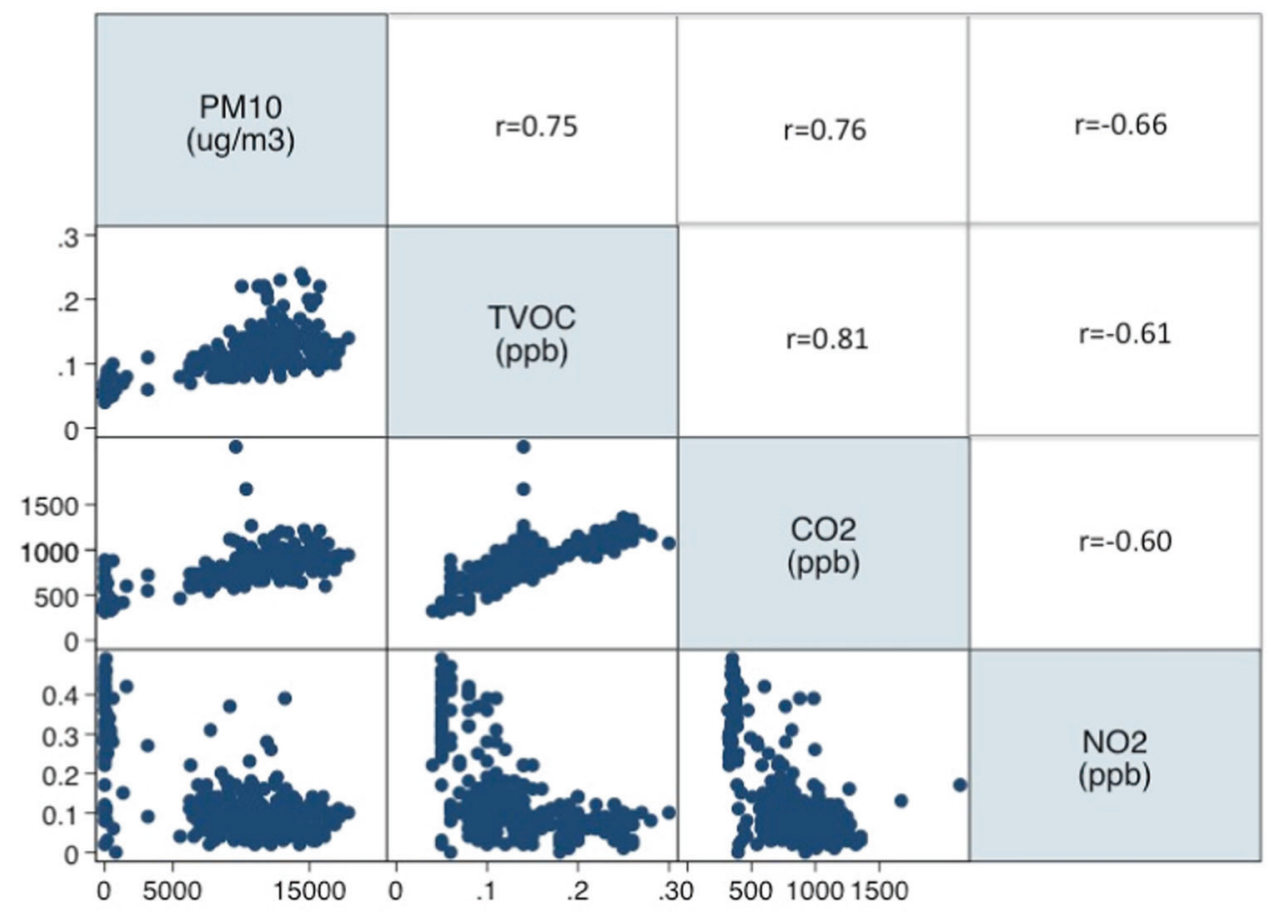

study to measure particulate matter, gases and airborne nicotine during a vaping convention with a large number of attendees. As e-cigarettes have become more popular [2], indoor e-cigarette use is a source of concern.

An increasing number of studies have assessed the impact of e-cigarette aerosol on indoor air quality, with mixed results. A study by Schripp (2013) using an $8-\mathrm{m}^{3}$ emission chamber found an increase in ultrafine particles (FP/UFP) and VOCs after e-cigarette use compared to background air [13]. In an observational study comparing $\mathrm{PM}_{2.5}$ measured during $1 \mathrm{~h}$ in the home of an e-cigarette user living in a smoke-free home, $\mathrm{PM}_{2.5}$ concentrations were higher compared to non-e-cigarette users living in smoke-free homes [10]. Another study using a laboratory room as an exposure chamber suggested that e-cigarette use was a source of secondhand exposure to nicotine but not to $\mathrm{PM}_{2.5}$ or VOCs [14]. Two doses of 70-ml e-cigarette aerosol were generated for each of the 12 experiments in this study and the mean 1-h concentration of nicotine was $2.51 \mu \mathrm{g} / \mathrm{m}^{3}$. Schober et al. showed an increase in indoor polynuclear aromatic hydrocarbons (PAHs) and airborne nicotine by mimicking a real vaping session of three volunteers using one e-cigarette each in a $45 \mathrm{~m}^{3}$ room. They found the mean $\mathrm{PM}_{2.5}$ was $197 \mu \mathrm{g} / \mathrm{m}^{3}$ during the sessions, which was 33fold higher than the concentration in the same room without use of e-cigarettes [24]. However, most previous studies were conducted in a chamber or an artificial environment, which may be different from real-world conditions. Additionally, previous studies assessed contaminants generated by a small number of e-cigarettes. Our study is the first evaluation of indoor air quality during a real vaping convention, characterized by a large number of people using e-cigarettes simultaneously [25].

In our study, the estimated 24-h time-TWA PM $_{10}$ was $1,800 \mu \mathrm{g} / \mathrm{m}^{3}$, which is 12 fold higher than the National Ambient Air Quality Standards (NAAQS) 24-h TWA PM 10 limit $\left(150 \mu \mathrm{g} / \mathrm{m}^{3}\right)$ established by the United States Environmental Protection Agency (EPA) and 36-fold higher than the air quality standards of the European Commission (50 $\left.\mu \mathrm{g} / \mathrm{m}^{3}\right)$. The peak $\mathrm{PM}_{10}$ concentration reached $17,860 \mu \mathrm{g} /$ $\mathrm{m}^{3}$. Furthermore, for more than $50 \%$ of the time during the vaping convention, the $\mathrm{PM}_{10}$ concentration stayed over $10,000 \mu \mathrm{g} / \mathrm{m}^{3}$, reaching the TWA inhalable particle guideline of the American Conference of Governmental Industrial Hygienists. This indicates a potential occupational hazard to $\mathrm{PM}_{10}$ exposure for vendors attending the whole event, and similar events frequently. Outdoor mean concentrations were calculated as $33 \mu \mathrm{g} / \mathrm{m}^{3}$ (median of $\left.12 \mu \mathrm{g} / \mathrm{m}^{3}\right)$.

Of note, the aerosol that is released from electronic cigarettes is a mix of volatile components with a high vapor pressure, and thus it undergoes rapid changes that result in changes in size distribution. This is one of the reasons we chose to collect $\mathrm{PM}_{10}$ instead of $\mathrm{PM}_{2.5}$, although some authors (Ingebrethsen et al. [23].) have described e-cigarette aerosols in the ultrafine to fine particle sizes. Two limitations of our sampling are that we did not calibrate the SidePak at the high concentrations found at the convention, and that the SidePak is calibrated against Arizona dust, which has very different optical properties from the aerosol 
encountered at this venue. Nevertheless, we have reasonable confidence in our real-time $\mathrm{PM}_{10}$ results because the integrated samples collected simultaneously (using filter calibration is an accepted protocol for direct reading devices) match the SidePak TWA within $1 \%$. In addition, real-time concentrations dropped to baseline during our time outside the venue, as shown in Fig. 2.

The median indoor TVOC concentrations of $0.13 \mathrm{ppm}$ during the vaping convention was 2 -fold higher than that of outdoor TVOC concentrations, suggesting that e-cigarettes are a source of TVOCs. However, we expected the difference between indoor and outdoor TVOC concentrations to be higher given the dense plumes observed during the event; the relatively small difference may reflect some problem with the sensor at the high concentrations found in the venue. Alternatively, some of the VOCs in the aerosol may have an IP greater than the lamp's energy and were not being ionized, or we may be losing particle-bound VOCs that are filtered out by the inlet membrane. The major organic compounds found in inhaled e-cigarette aerosol are propylene glycol and glycerol [15]. Goniewicz et al. reported that toxic or carcinogenic VOCs including formaldehyde, acetaldehyde, acrolein, toluene, and p,m-xylene were found in most of the 12 types of e-cigarette aerosol generated in their study [12]. However, few studies have characterized VOCs in the exhaled aerosol.

The average indoor nicotine concentration of $124.7 \mu \mathrm{g} / \mathrm{m}^{3}$ in our study was similar to secondhand smoke nicotine measured in nightclubs and pubs when cigarette smoking was permitted in the US [26] and Canada $\left(94.5 \mu \mathrm{g} / \mathrm{m}^{3}\right)$ [27]. This concentration is 88 times higher than the average concentration of $1.42 \mu \mathrm{g} / \mathrm{m}^{3}$ measured in waterpipe cafes in Baltimore [28]. Secondhand tobacco smoke causes both fatal and nonfatal cardiac disease [29, 30]. Some but limited evidence also supports that e-cigarette aerosol can induce cardiovascular disease [30]. Additional studies are needed to evaluate whether individual compounds of hazardous VOCs and/or aerosol nicotine generated from e-cigarettes can impact people's health.

Outdoor $\mathrm{NO}_{2}$ concentrations were about twice the indoor $\mathrm{NO}_{2}$, as we expected [31]. Indoor $\mathrm{NO}_{2}$ concentrations in the venue did not exceed the recommended exposure limit of 1 ppm from the National Institute for Occupational Safety and Health (NIOSH). Indoor $\mathrm{NO}_{2}$ concentration with a mean of $0.10 \mathrm{ppm}$ and a peak concentration of $0.49 \mathrm{ppm}$ exceeded the US National Ambient Air Quality Standards (NAAQS) of 1-h daily maximum of $100 \mathrm{ppb}(0.10 \mathrm{ppm})$, indicating potential health risks, especially to susceptible and vulnerable populations including asthmatics and disproportionately exposed groups. The indoor $\mathrm{NO}_{2}$ concentrations, however, were possibly related to outdoor concentrations and not due to the use of e-cigarettes [25].
The $\mathrm{CO}_{2}$ concentrations are typically used as an indicator of the ventilation adequacy and occupant densities, as there was no other source of $\mathrm{CO}_{2}$ other than normal respiration in the venue based on our observation. The difference between median indoor and outdoor $\mathrm{CO}_{2}$ concentration was 422 ppm, almost $60 \%$ of the guideline of a $700-p p m$ difference from the American Society of Heating, Refrigeration and Air Conditioning Engineers (ASHRAE) (ANSI/ASHRAE 62-2001). The comparison of the indoor/outdoor $\mathrm{CO}_{2}$ concentration difference in the ASHRAE guideline is used to determine if air exchange and ventilation are satisfactory. Our finding indicates that if we were only to use $\mathrm{CO}_{2}$ concentrations, ventilation would be determined adequate during the convention. However, as can be seen from Fig. 1, the venue was not being ventilated adequately. This could be explained by interference of some of the aerosol components with the $\mathrm{CO}_{2}$ sensor. The sensor in our probe detects $\mathrm{CO}_{2}$ in the infrared wavelengths. Ideally, other gas molecules do not absorb light at the same wavelength as $\mathrm{CO}_{2}$, and do not affect the amount of light reaching the detector; however, some cross-sensitivity is possible, and the unknown nature of the e-cigarette mix makes interference likely. Furthermore, condensation on the sensor may lead to errant readings. Even though relative humidity (RH) was not of concern, some components of the aerosol may be condensing on the sensor. We also noted that ventilation was being reduced on purpose, especially during the competitions, as organizers called for closing of doors and windows in order to increase the visibility of the generated plumes. Higher $\mathrm{PM}_{10}$ and TVOC concentrations were closely correlated with elevated $\mathrm{CO}_{2}$ concentrations, supporting that exhaling was the major source of $\mathrm{PM}_{10}$ and TVOCs (Fig. 3). Increased indoor use of e-cigarettes and poor ventilation conditions will increase the indoor $\mathrm{PM}_{10}$ and TVOCs levels from vaping, thus aggravating the indoor air quality.

A limitation of this study was that we only conducted sampling in one vaping convention, so we cannot generalize to all scenarios. Additional variables such as ventilation rate and number of active e-cigarette users need to be quantitatively measured for future studies. In addition to $\mathrm{PM}_{10}$, TVOCs, $\mathrm{NO}_{2}$ and nicotine- the chemicals measured in our study-other potential toxic components related to indoor air quality should be assessed, including $\mathrm{PM}_{2.5}$, ultra-fine particles, individual components of VOCs such as PAHs, TSNAs, aldehydes and 4-(methylnitrosamino)-1-(3-pyridyl)-1- butanone (NNK). Another limitation of our study is that our VOC and PM instruments are typically used for screening purposes, and were not calibrated at high concentrations. Thus, the results are most useful when considering relative concentrations. In order to validate VOC results, integrated samples, such as sampling with sorbent 
tubes analyzed with gas chromatography may need to be used in future studies.

Our study has several strengths. First, our air sampling was conducted outside of the laboratory setting and in a real-world situation with a large number of people using ecigarettes. This avoids potential differences associated with the aerosol generated by smoking machines and shows the real indoor air quality conditions in a vaping convention, including the amount of people, venue size, ventilation conditions, and large varieties of e-cigarette devices and e-liquids. Another strength is that we collected some integrated samples to validate our PM results. In addition, personal sampling was conducted by carrying backpacks, reflecting breathing zone exposure of convention attendees.

Our study confirms that e-cigarette aerosol is a major source of indoor air pollution of $\mathrm{PM}_{10}$, TVOCs, and air nicotine, which impairs indoor air quality. Attendees and vendors are exposed to high concentrations of hazardous pollutants during a vaping convention. The findings raise an occupational concern for e-cigarette vendors who attend vaping conventions on a regular basis in addition to being exposed at local vape shops during working hours, as well as other venue workers such as food vendors and cleaning personnel. Furthermore, extremely high concentrations of e-cigarette aerosol may cause third-hand exposure, since it can be expected that the surfaces in the exhibition hall become impregnated with deposited aerosol (solvents and nicotine), and nicotine exposure may happen via direct skin contact.

The FDA finalized a rule in August 2016 extending their regulatory authority to all e-cigarette products; however, the rule does not restrict their use in public places. A 2017 report [31] lists 12 US states and over 600 local laws restricting use of e-cigarette use in indoor public places. However, Maryland does not have a state ban, and only Baltimore city and three counties have restrictions on e-cigarettes in public places. Baltimore County, where the convention was held, has no restriction [9]. These results can inform FDA policy by supporting restricting use of e-cigarettes indoors, and recommending worker protections at vaping venues, such as vape shops and lounges. Protections may include increased ventilation, and requiring extensive cleaning procedures after each convention, to minimize potential third-hand exposure to future users of the venue.

Acknowledgements This study was supported by the Cigarette Restitution Fund (State of Maryland) grant number PHPA-G2034. PO was supported by the Alfonso Martín Escudero Foundation (Postdoctoral Fellowship 2014). AA is supported by the American Heart Association Tobacco Regulation and Addiction Center (Grant \# 1P50HL120163). We would like to thank Gillian Bailey Branam for her invaluable support with this work.

\section{Compliance with ethical standards}

Conflict of interest The authors declare that they have no conflict of interest.

Open Access This article is licensed under a Creative Commons Attribution 4.0 International License, which permits use, sharing, adaptation, distribution and reproduction in any medium or format, as long as you give appropriate credit to the original author(s) and the source, provide a link to the Creative Commons license, and indicate if changes were made. The images or other third party material in this article are included in the article's Creative Commons license, unless indicated otherwise in a credit line to the material. If material is not included in the article's Creative Commons license and your intended use is not permitted by statutory regulation or exceeds the permitted use, you will need to obtain permission directly from the copyright holder. To view a copy of this license, visit http://creativecommons. org/licenses/by/4.0/.

\section{References}

1. National Institute on Drug Abuse (NIDA). DrugFacts: electronic cigarettes (e-Cigarettes), Bethesda, MA. https://www.drugabuse. gov/publications/drugfacts/electronic-cigarettes-e-cigarettes Accessed 14 Dec 2016.

2. Giovenco DP, Hammond D, Corey CG, Ambrose BK, Delnevo CD. E-Cigarette market trends in traditional U.S. retail channels, 2012-2013. Nicotine Tob Res. 2015;17:1279-83.

3. Schoenborn CA, Gindi RM Electronic cigarette use among adults: United States, 2014. NCHS Data Br. 2015;217:1-8.

4. US Centers for Chronic Disease Prevention (CDC). CDC vital signs e-cigarette ads and youth, Atlanta, GA https://www.cdc.gov/ vitalsigns/ecigarette-ads/ Accessed 14 Dec 2016.

5. Mangalindan JP. For e-cigarette makers, a $\$ 10$ billion market at stake, Tampa, FL 2016. http://fortune.com/2014/05/01/for-e-ciga rette-makers-a-10-billion-market-at-stake/ Accessed 14 Dec 2016.

6. Williams RS. VapeCons: e-cigarette user conventions. J Public Health Policy. 2015;36:440-51.

7. Jarmul S, Aherrera A, Rule AM, Olmedo P, Chen R, Navas-Acien A. Lost in e-cigarette clouds: a culture on the rise. AJPH. 2017;107:265-6.

8. Goniewicz ML, Kuma T, Gawron M, Knysak J, Kosmider L. Nicotine levels in electronic cigarettes. Nicotine Tob Res. 2013;15:158-66.

9. U.S. Food and Drug Administration (FDA). The facts on the FDA's new tobacco rule. https://www.fda.gov/ForConsumers/ ConsumerUpdates/ucm506676.htm Accessed 25 May 2017.

10. Fernández E, Ballbè M, Sureda X, Fu M, Saltó EM-SJ. Particulate matter from electronic cigarettes and conventional cigarettes: a systematic review and observational study. Curr Env Heal Rep. 2015;2:423-9.

11. Grana R, Benowitz N, Glantz SA. E-cigarettes: a scientific review. Circulation. 2014;129:1972-86.

12. Goniewicz ML, Knysak J, Gawron M, Kosmider L, Sobczak A, Kurek J, et al. Levels of selected carcinogens and toxicants in vapour from electronic cigarettes. Tob Control. 2014;23:133-9.

13. Schripp T, Markewitz D, Uhde E, Salthammer T. Does e-cigarette consumption cause passive vaping? Indoor Air. 2013;23:25-31.

14. Czogala J, Goniewicz ML, Fidelus B, Zielinska-Danch W, Travers MJ, Sobczak A. Secondhand exposure to vapors from electronic cigarettes. Nicotine Tob Res. 2014;16:655-62.

15. O'Connell G, Colard S, Cahours X, Pritchard J. An assessment of indoor air quality before, during and after unrestricted use of 
e-cigarettes in a small room. Int $\mathbf{J}$ Environ Res Public Health. 2015;12:4889-907.

16. WHO. Conference of the Parties to the WHO Framework Convention on Tobacco Control Electronic nicotine delivery systems Report by WHO, Moscow. http://www.who.int/fctc/cop/cop7/ FCTC_COP_7_11_EN.pdf Accessed 14 Dec 2016.

17. Husari A, Shihadeh A, Talih S, Hashem Y, El Sabban M, Zaatari G. Acute Exposure to electronic and combustible cigarette aerosols: effects in an animal model and in human alveolar cells. Nicotine Tob Res. 2016;18:613-9.

18. Board of Science and the Occupational Medicine Committee (BMA). BMA calls for stronger regulation of e-cigarettes, London. http://bma.org.uk/-/media/Files/PDFs/Working\%20for\%20change/ Improving\%20health/tobaccoecigarettespublicplaces_jan2013.pdf Accessed 14 Dec 2014.

19. Mishra A, Chaturvedi P, Datta S, Sinukumar S, Joshi P, Garg A. Harmful effects of nicotine. Indian $\mathrm{J}$ Med Paediatr Oncol. 2015;36:24-31.

20. Hammond SK, Leaderer BP. A diffusion monitor to measure exposure to passive smoking. Environ Sci Technol. 1987;21: 494-7.

21. López MJ, Fernández E, Pérez-Rios M, Martínez-Sánchez JM, Schiaffino A, Galán I, et al. Impact of the 2011 Spanish smoking ban in hospitality venues: indoor secondhand smoke exposure and influence of outdoor smoking. Nicotine Tob Res. 2013;15:992-6.

22. Plog BA, Niland J, Quinlan P. Fundamentals of industrial hygiene. 4th edn. Washinton DC: National Safety Council; 1996.

23. Ingebrethsen BJ, Cole SK, Alderman SL. Electronic cigarette aerosol particle size distribution measurements. Inhal Toxicol. 2012;24:976-84.
24. Schober W, Szendrei K, Matzen W, Osiander-Fuchsb H, Heitmannc D, Schettgen T, et al. Use of electronic cigarettes (e-cigarettes) impairs indoor air quality and increases FeNO levels of e-cigarette consumers. Int J Hyg Environ Health. 2014;217: 628-37.

25. US Environmental Protection Agency (US EPA). Nitrogen dioxide's impact on indoor air quality, Washington, DC. https://www. epa.gov/indoor-air-quality-iaq/nitrogen-dioxides-impact-indoor-a ir-quality Accessed 14 Dec 2016.

26. Eatough DJ, Benner CL, Tang H, Landon V, Richards G, Caka FM, et al. The chemical composition of environmental tobacco smoke III. Identification of conservative tracers of environmental tobacco smoke. Environ Int. 1989;15:19-28.

27. Collett CW, Ross JA, Levine KB. Nicotine, RSP, and CO2 levels in bars and nightclubs. Environ Int. 1992;18:347-52.

28. Torrey CM, Moon KA, Williams DAL, Green T, Cohen JE, Navas-Acien A, et al. Waterpipe cafes in Baltimore, Maryland: Carbon monoxide, particulate matter, and nicotine exposure. J Expo Sci Environ Epidemiol. 2015;25:405-10.

29. Glantz SA, Parmley WW. Passive smoking and heart disease. JAMA. 1995;273:1047.

30. Whincup PH, Gilg JA, Emberson JR, Jarvis MJ, Feyerabend C, Bryant A, et al. Passive smoking and risk of coronary heart disease and stroke: prospective study with cotinine measurement. BMJ. 2004;329:200-5.

31. American nonsmokers rights foundation. States and Municipalities with Laws Regulating Use of Electronic Cigarettesyear: 2017 www.no-smoke.org/download.php?file=/pdf/ecigslaws.pdf. 